\title{
RETRACTED ARTICLE: The mechanisms of action of Ivermectin against SARS-CoV-2: An evidence-based clinical review article
}

\author{
Asiya Kamber Zaidi $\mathbb{1}^{1,2} \cdot$ Puya Dehgani-Mobaraki ${ }^{3}$
}

Received: 11 May 2021 / Revised: 17 May 2021 / Accepted: 20 May 2021 / Published online: 15 June 2021

(c) The Author(s), under exclusive licence to the Japan Antibiotics Research Association 2021

The Editor-in-Chief has retracted this article. Following publication, concerns were raised regarding the methodology and the conclusions of this review article. Postpublication review confirmed that while the review article appropriately describes the mechanism of action of ivermectin, the cited sources do not appear to show that there is clear clinical evidence of the effect of ivermectin for the treatment of SARS-CoV-2. The Editor-in-Chief therefore no longer has confidence in the reliability of this review article. None of the authors agree to this retraction. The online version of this article contains the full text of the retracted article as Supplementary Information.

Supplementary Information The online version of this article (https://doi.org/10.1038/s41429-021-00430-5) contains supplementary material, which is available to authorized users.

Asiya Kamber Zaidi

asiyazaidia@gmail.com

1 Member, Association "Naso Sano" Onlus, Umbria Regional Registry of volunteer activities, Corciano, Italy

2 Mahatma Gandhi Memorial Medical College, Indore, India

3 President, Association "Naso Sano" Onlus, Umbria Regional Registry of volunteer activities, Corciano, Italy 